\title{
THE DRIFT OF THE ICE-BREAKER SEDOV
}

\author{
By Prof. N. N. Zubov
}

\section{A}

TTEMPTS have been made by many expeditions to penetrate to the central part of the Arctic Ocean. A few have even succeeded in reaching the North Pole itself. After several unsuccessful attempts, the American explorer Robert Peary, on April 6, 1909, reached the North Pole on sledges drawn by dogs and remained there for some thirty hours. On May 9, 1926, the American aviator, Admiral Richard Byrd, flew to the Pole by aeroplane and describing a circle in the air, returned safely to Spitsbergen, the starting point of the flight. In the same year, the Norwegian explorer Amundsen crossed the Arctic Ocean from Spitsbergen to Alaska in a dirigible, flying over the North Pole on May 12. On May 24, 1928, the Italian expedition of General Nobile also succeeded in reaching the North Pole in a dirigible, which circled over it; but the expedition met with disaster on the return flight and some of the members perished.

Concerted attempts to reach the North Pole were made by Soviet explorers in 1937, in which year nine Soviet aeroplanes flew over the Pole. While the North Polar Station on the drifting icefloe was being set up, there were present at the Pole four heavy aeroplanes and thirty-three Soviet polar explorers. During those days five aeroplanes, piloted by Molokov, Golovin, Vodopianov, Alexeyev and Mazuruk, flew over the Pole. On June 18, 1937, Chkalov's machine passed over the Pole on his flight from Moscow to the United States. On July 13, 1937-following the same route-Gromov flew his machine over the North Pole; on August 13, Levanevsky flew over the North Pole on his way to America. Levanevsky was afterwards lost and during the search for his machine, Vodopianor flew over the Pole on October 7, 1937, and Moshkovsky on April 4, 1938.

\section{ForERUNNERS OF THE Sedov}

Only three expeditions have drifted with the ice in the Arctic : Nansen's expedition of 1893-96 on the Fram, Papanin's North Polar expedition on the drifting icefloe of 1937-38, and the expedition of the Soviet polar explorers on the ice-breaker Sedov (NATURE, 143, 837 ; 1939).

Nansen's expedition did not reach the North Pole. During her drift the Fram only reached lat. $85^{\circ} 56^{\prime} \mathbf{N}$. Yet it was Nansen who, in a scientific sense, literally discovered the Arctic Ocean. Prior to the drift of the Fram very little indeed was known about this ocean. Nansen himself did not expect to find depths exceeding $500 \mathrm{~m}$. (1,640 ft.) and consequently did not take with him the necessary equipment for sounding great depths.

From Nansen's expedition it was learned that the Arctic Ocean was a sea having depths of more than $3,000 \mathrm{~m}$. $(9,843 \mathrm{ft}$.$) . The warm Atlantic$ waters-a branch of the Gulf Stream-were shown to penetrate as a deep current far into the central part of the Arctic Ocean. Nansen's observations revealed the primary conditions of the movement of the ice in this basin. Lastly, Nansen also studied the principal conditions governing the formation, development and disintegration of sea ice. There is not an aspect of oceanography and geophysics relating to the Arctic Ocean to which Nansen's expedition did not make important discoveries.

On May 21, 1937, with the help of four heavy aeroplanes, the Pananin expedition was landed on the ice. On a big icefield the Soviet polar explorers set up a well-equipped polar observatory. On June 6 the organization of the North Polar Station was completed. The aeroplanes flew back to the mainland, leaving Papanin, Krenkel, Shirshov and Fedorov on the ice. They remained on the icefloe for 274 days. During this period the icefield of the Papanin expedition was carried from the North Pole to the east coast of Greenland where, at lat. $70^{\circ} 54^{\prime} \mathrm{N}$. and long. $19^{\circ} 48^{\prime} \mathrm{W}$., the drifting expedition was taken off by the ice-breakers Taimyr and Murman.

The men of the expedition on the drifting icefloe measured all depths along the entire course of their drift from the North Pole to the coast of Greenland. They revealed the movement of the ice and sea current under the ice which had escaped Nansen's attention. They refuted Nansen's theory that no life existed in the central part of the Arctic Ocean. They carried out valuable observations on terrestrial magnetism. The meteorological observations of the Papanin expedition not only facilitated the organization of the trans-Arctic flights of Chkalov and Gromov, but also contributed to our knowledge of the structure of the atmosphere and the processes determining the weather in the central part of the Arctic. 


\section{Start of the Sedov Drift}

Contrary to the drifts of the Fram and the North Polar Expedition on the drifting icefloe, the drift of the Sedov was not deliberately planned. With he ice-breakers Sadko and Malygin, on October 23, 1937, the Sedov was caught in the ice in the Laptev sea at lat. $75^{\circ} 19^{\prime} \mathrm{N}$. and long. $132^{\circ} 25^{\prime} \mathrm{E}$. On August 28, 1938, these ice-breakers were at lat. $33^{\circ} 06^{\prime}$ N., long. $138^{\circ} 24^{\prime} \mathrm{E}$. On that day the ce-breaker Yermak extricated the Sadko and Malygin from the ice and brought them into clear water. The Sedov, however, could not be released swing to the fact that during her imprisonment in the ice she had sustained some damage to her steering gear.

Fifteen volunteers, headed by Captain Badygin, remained on the Sedov; and from that time the vessel continued her remarkable drift in the most inaccessible part of the Arctic Ocean, where no other vessel had ever drifted before and no aeroplane had flown.

Several circumstances make the drift of the Sedov of exceptional interest. First, the drift of the ice-breaker began at a time when the North Polar Expedition on the drifting icefloe was still making observations. Thus, uninterrupted observations of the central parts of the Arctic Ocean were being conducted. Secondly, soon after the commencement of the drift of the Sedov and also in the Lapter Sea but in the south-western part, there began the drift of several vessels headed by the ice-breaker Lenin. These vessels had been carried from Khatanga Bay. The drift of the icebreaker Lenin ended on August 7, 1938, when, with the entire caravan of ships, she was extricated from the ice by the Krassin. Thus, for nine months two caravans of ships drifted simultaneously at some distance from each other, one in the south-western part of the Laptev Sea, the other in the northeastern part of the same sea, and in the region to the north of the New Siberian Islands.

A comparison of these drifts has yielded noteworthy results. Differing from each other in details, these drifts at the same time reveal extraordinary similarity, a fact which goes to show that they were conditioned by the same causes: the prevailing winds and constant currents.

Thirdly, soon after the commencement of her drift, the Sedov found herself in the region where the drift of Nansen's Fram started.

A comparison of the subsequent courses of the drifts of the Fram and the Sedov is of exceptional interest, because the former took place in climatic conditions differing considerably from those of the present day. At first the Sedov drifted directly northwards. In a month, under the influence of west winds the ice-breaker turned eastwards, and early in January, 1938, reached the most easterly point of her course-lat. $78^{\circ} 25^{\prime} \mathrm{N}$. and long. $153^{\circ} 26^{\prime} \mathrm{E}$. From that time the Sedov began slowly to move westwards, at the same time going more and more to the north. She continued this northwesterly direction, and on March 22, 1939, reached lat. $86^{\circ} 34 \cdot 7^{\prime} \mathrm{N}$. and long. $108^{\circ} 50^{\prime} \mathrm{E}$. Later, the drift began gradually to incline to the south-west. From May 17 until July 27, 1939, the courses of the Sedov and the Fram overlap, as it were, but afterwards the Sedov again commenced to go rapidly to the north, and on August 29, 1939, reached the northernmost point of her drift, lat. $86^{\circ} 39 \cdot 5^{\prime} \mathrm{N}^{\prime}$., long. $47^{\circ} 55^{\prime} \mathrm{E}$. After that the Sedov again descended to the south, crossing the Fram's course, and along a line lying between the drifts of the expedition on the drifting icefloe and that of the Fram, made for the broad strait dividing Greenland from Spitsbergen. From December 1, 1939 , the Sedov was finally drawn into the drift of the ice moving from the Arctic Basin to the Greenland Sea; with gradually increasing speed the ice-breaker drifted almost due south. On January 1, 1940, she had already reached lat. $81^{\circ} 15 \cdot 4^{\prime} \mathrm{N}$., long. $4^{\circ} 16^{\prime} \mathrm{E}$. She was afterwards extricated from the ice by the ice-breaker, Joseph Stalin. Her crew was taken off the vessel on January 13, and on January 29, 1940, the Sedov arrived in Murmansk.

\section{END OF A LEGEND}

One achievement of the Sedov is the final explosion of the Sannikov Land legend. In 1811 Jacob Sannikov purported to have sighted from the northern coast of Kotelny Island a high land which he attempted to reach by crossing the ice; he was prevented from doing so by a big polynia (an expanse of clear water in the icefield). According to Sannikov, there remained only another

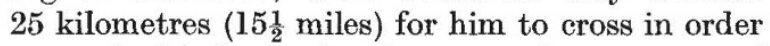
to reach this land. Doubts as to the existence of this supposed land have, however, been held by many for several decades.

The Sedov, during the period of her drift, twice crossed the region of the supposed land: once from west to east, approximately at the 78th parallel, and the second time from the south-east to the north-west. Later, the air expedition of Alexeyer passed over the region approximately in a meridianal direction. The flights were from the northern extremity of Kotelny Island to the drifting caravan of vessels, the Sadko, Sedov and Malygin, and were made at a time when visibility was excellent.

Through this same region also passed the icebreakers Yermak and Joseph Stalin on their way to meet the drifting vessels. Yet neither icebreaker saw any sign of 'Sannikov Land'. 


\section{Boundary of the Laptev Sea}

From the point of view of physical geography, the Laptev Sea is not a sea but only a gulf of the Arctic Ocean. The northern boundary of this sea is conditional, having been fixed by the Soviet Government as the arc of the great circle connecting Cape Molotov (the northern point of Severnaya Zemlya) with the point at which the meridian crosses the northern point of Kotalny Island (long. $139^{\circ} \mathrm{E}$.) and the edge of the continental shelf. The drift of the Sedov from the beginning up to lat. $79^{\circ} 37^{\prime} \mathrm{N}$., long. $149^{\circ} 58^{\prime} \mathrm{E}$. proceeded along the continental shelf. The depths did not exceed $200 \mathrm{~m}$. However, at lat. $79^{\circ} 52^{\prime} \mathrm{N}$., long. and long. $39^{\circ} 25^{\prime} \mathrm{E}$. the expedition failed to find bottom at $5,180 \mathrm{~m}$.

Extremely interesting are the soundings obtained by the Sedov in the latter stages of her drift-at the entrance to the Greenland Sea. Nansen surmised that between the north-eastern extremity of Greenland and the north-western extremity of Spitsbergen was a submarine ridge separating the great depths of the Arctic Ocean from the great depths of the Greenland Sea. This ridge came to be known as Nansen's submarine ridge. Its eastern part was studied in 1935 by the Sadko expedition, and the western part by the Papanin North Polar Expedition on the drifting icefloe. The Sedov crossed Nansen's submarine ridge in

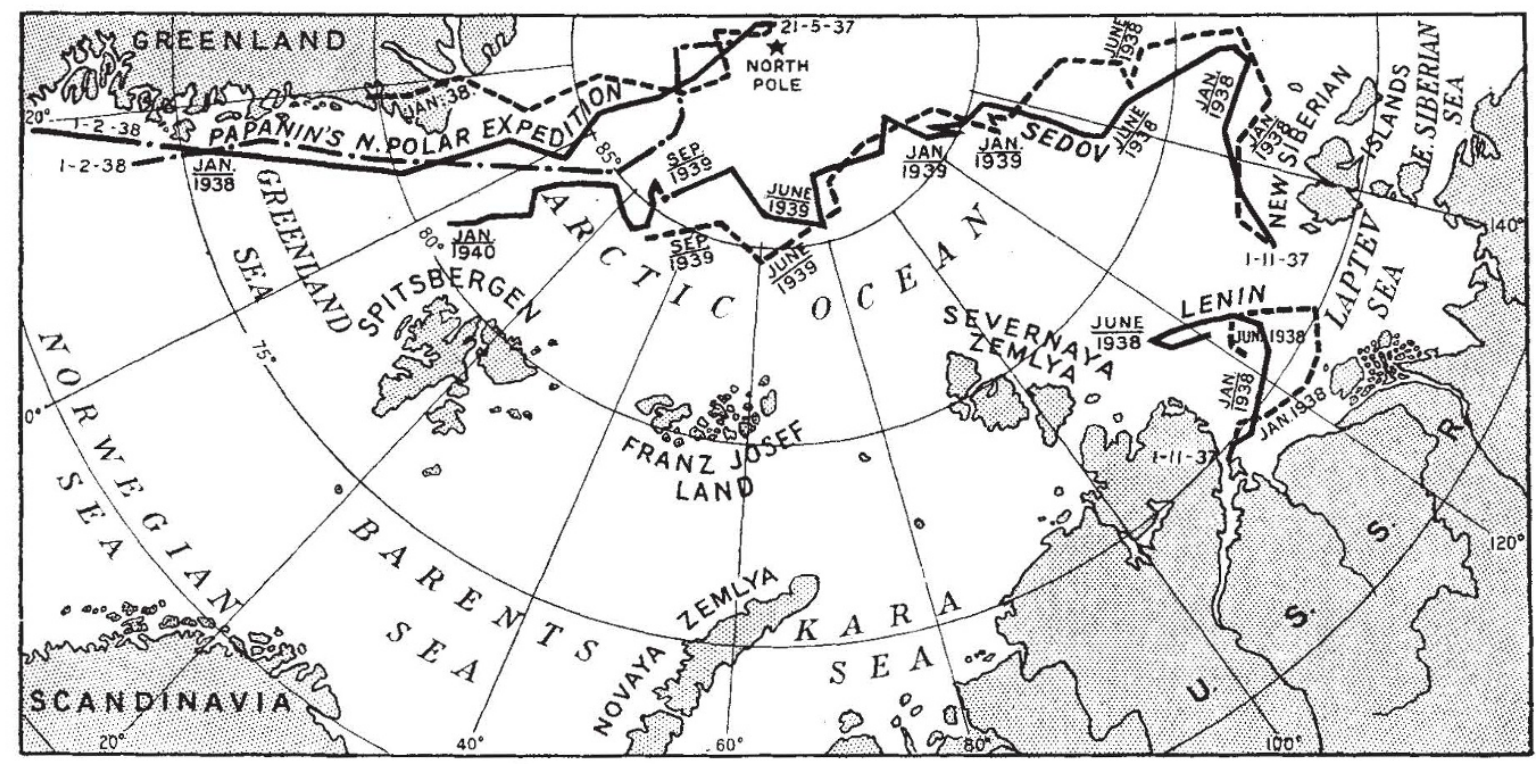

The Russian Drifts.

ACTUAL DRIFT, - ..... THEORETICAL DRIFT WITHOUT ACCOUNT OF CONSTANT CURRENTS, - - - THEORETICAL DRIFT WITH ACCOUNT OF CONSTANT CURRENTS.

$148^{\circ} 02^{\prime}$ E., the Sedov found herself over depths considerably exceeding $3,000 \mathrm{~m}$., that is, at depths characteristic of the deep bed of the central part of the Arctic Ocean.

The region lying to the north of the New Siberian Islands has been thoroughly sounded. From a comparison of these soundings, it appears most probable that the continental shelf at the Kotelny Island meridian (long. $139^{\circ}$ E.) ends at lat. $78^{\circ} 30^{\prime} \mathrm{N}$. This must be considered as the north-eastern point of the Laptev Sea.

As was found in the region of the New Siberian Islands, the continental shelf stretches farther north than was supposed, and the continental slope is much more gradual. It occupies $2^{\circ}$ of latitude and has a gradient of not more than 1 .

To the north of Franz Josef Land great depths were unexpectedly discovered. At lat. $86^{\circ} 26^{\circ} 6^{\prime} \mathrm{N}$., its middle part, at lat. $81^{\circ} 34^{\prime} \mathrm{N}$., long. $4^{\circ} 40^{\prime} \mathrm{E}$., and registered a depth of $1,500 \mathrm{~m}$., thus confirming the existence of this ridge.

\section{Changes in the Thermal Balance}

In addition to the sounding of depths, the Sedov crew carried out meteorological, hydrological, magnetic and gravimetrical observations along the same lines as the members of the North Polar Expedition on the drifting icefloe. The observations of the Sedov crew confirmed what has already been recorded by the Papanin expedition and by Nansen : on the whole course of their drift they discovered at intermediate depths warm waters of Atlantic origin.

The fact that the lines of the drifts of the Fram and the Sedov crossed in several places has made it 
possible to determine the changes in the thermal balance of the Arctic Basin during the last fortyfive years.

The Sedov remained twice as long beyond the 85th parallel as the North Polar Expedition on the drifting icefloe, and two and a half times as long as the Fram, though the drift of the latter lasted nearly three years. The Sedov began her drift considerably farther south than the Fram, and at the end of it she descended to more southerly latitudes than Nansen's vessel, yet the Sedov's drift lasted only $26 \frac{1}{2}$ months. This indicates that the speed of the Sedov's drift was considerably greater than that of the Fram.

The increased movement of ice from the Arctic Basin into the Greenland Sea is accompanied by an increase in the flow of warm Atlantic waters into the polar basin, a reduction in the volume of ice in seas bordering on the Aretic, a decrease in the thickness of polar ice and size of glaciers, and also by a rise in the winter temperatures of the air. All these phenomena are characteristic of the warmer temperatures we are now observing in the Arctic.

Notwithstanding the fact that the line of the Sedov's drift was considerably more northerly than the line of the Fram's drift, the winter months in the Arctic in Nansen's time were several degrees colder than at the present time. The lowest temperature of the air $\left(-44 \cdot 1^{\circ}\right)$ was registered by the Sedov's crew on March 10,1939 , at lat. $86^{\circ} 23^{\prime} \mathrm{N}$., long. $110^{\circ} 20^{\prime} \mathrm{E}$. The lowest temperature during the drift of the Fram $\left(-52^{\circ}\right)$ was registered on January 15,1896 , approximately at lat. $84^{\circ} 55^{\prime} \mathrm{N}$., long. $41^{\circ} \mathrm{E}$., that is, appreciably more south-west than the spot where the Sedov's lowest temperature was registered and where, as a rule, it is warmer.

The thickness of level ice according to the measurements of the Sedov'screw was not more than $218 \mathrm{~cm} .(7 \mathrm{ft} .2 \mathrm{in}$.). Nansen's expedition encountered ice $365 \mathrm{~cm}$. in thickness. Analysis has shown that the lesser thickness of the ice in the region of the Sedov's drift was due not so much to the rise of the winter temperatures of the air as to the melting of the ice in recent years in summer time.

\section{BeLt OF HuMmocks}

In the light of the observations made by the Sedov's crew, interest is attached to questions concerning the maximum thickness of the ice. The members of the North Polar Expedition on the drifting icefloe never encountered ice of a greater thickness than $218 \mathrm{~cm}$. That being the case, where was the icefield on which the expedition set up its observation station formed, and how did it reach the North Pole? We know that this icefield was more than $3 \mathrm{~m}$. thick. Why was the Sedov, which on March 22, 1939, was $180 \mathrm{~km}$. (97·12 nautical miles) farther to the north than the Fram and afterwards, like the Fram, turned westwards, unable to penetrate to the 87th parallel ? The highest latitude reached by the $\mathrm{Fram}$ was $85^{\circ} 55^{\circ} 5^{\prime}$; the highest latitude reached by the Sedov was $86^{\circ} 39 \cdot 5^{\prime}$. The northernmost point reached by Nansen during his sledge journey to the North Pole was lat. $86^{\circ} 14^{\prime}$; lastly, in 1900 Cagni in the same region reached lat. $86^{\circ} 34^{\prime} \mathrm{N}$. Both Nansen and Cagni were prevented from going farther north by impenetrable hummocky ice.

These data should be compared with the observations made by Alexeyev during his flights from Franz Josef Land to the North Pole and back. Alexeyev ascertained that from Rudolf Island up to lat. $82^{\circ} 30^{\prime} \mathrm{N}$. lie hummocky fields of young ice dotted with icebergs. Higher, up to lat. $85^{\circ} 30^{\prime} \mathrm{N}$., the size of the icefields increases, reaching $20 \mathrm{~km}$. across. On these fields are level platforms suitable for the landing of aeroplanes. At the 84th parallel the thickness of the ice did not exceed 100-120 cm. Beyond $85^{\circ} 30^{\prime}$ commenced an icefield of ice many years old, while up to the 86 th parallel the icefields were small and hummocky, and the lanes between the icefields were filled with broken ice. In these places it was impossible to land aeroplanes. Farther north, particularly between $87^{\circ}$ and $88^{\circ} 30^{\prime}$, the icefields appeared more suitable for landing-places. The condition of the ice in the region of the North Polar Expedition on the drifting icefloe is already known.

From the foregoing, we see that between the North Pole and Franz Josef Land is situated a belt of hummocks of a peculiar character. This belt separates the younger ice, formed mainly on the continental shelf of Eurasia, from the thicker ice near the North Pole. It seems that this belt of hummocks which, in its time, had stopped the further advance to the north of Nansen and Cagni, is a permanent feature.

\section{NANSEN'S LAWS}

Four times a day the men on the Sedov transmitted by radio their position and meteorological observations. This made possible a comparison of the ice drift with the wind causing the drift. Such observations made near coasts are usually distorted by the nearness of land and shallows; and so, for a theoretical study we are only able to use the data supplied by three drifts, those of the Fram, of the Papanin North Polar Expedition on the drifting icefloe (while it was in the central part of the Arctic Ocean) and of the Sedov.

Like all known drifts, the drift of the Sedov did not proceed in a straight line. The ice-breaker often turned back on her course, described zigzags 
and even loops. These changes of direction were caused by changes in the direction and velocity of the wind. In this connexion, very characteristic vre the figure 8 described by the Sedov between October 2 and 26 , and the zigzags between November 10 and 30,1938 , and the loop she made between January 3 and 17, 1939.

The only difference between the direction of the drift and the direction of the wind was that the drift was deflected $30^{\circ}-40^{\circ}$ to the right. Any deviation from this law can be attributed to the incompleteness of the Sedov's observations at my disposal.

The observations of the Sedov worked out by me show that in the region where the Sedov drifted between September 1, 1938, and February 1, 1939, the constant current was so weak that it might be said to have been absent. As a result, almost laboratory conditions prevailed for the study of the relations between wind and drift. Far removed from the distorting influence of land and constant currents, the wind drift was shown here practically in its pure form.

In this way it was possible to confirm yet again the exactness of the two simple laws of Nansen determining the behaviour of solid ice in the central part of the Arctic Basin. These laws are as follows :

(1) The speed of the wind drift is approximately one fiftieth of the velocity of the wind causing the drift.

(2) The drift of the ice is deflected from the direction of the wind by $30^{\circ}-40^{\circ}$ to the right owing to the influence of the deflecting force of the earth's rotation.

\section{Two Additional Laws}

A study of the drift of the Sedov makes it possible to add to Nansen's two laws two other equally simple laws :

(3) The drift of the ice follows the isobars. The ice drifts along these lines in such a way that the region of high pressure is to the right of the direction of the drift, and the region of low pressure to the left.

(4) The drift of the ice takes place at a speed proportional to the gradient of atmospheric pressure, or in other words, inversely as the distance between the isobars.

The first of these additional laws is not difficult to deduce. In moderate and high latitudes the wind, due to friction against the surface of the earth and to the influence of the deflecting force of the earth's rotation, is directed approximately $30^{\circ}-$ $40^{\circ}$ to the left of the corresponding isobar. The drift of the ice, according to the second of Nansen's laws, is deflected from the direction of the wind approximately by $30^{\circ}-40^{\circ}$ to the right. Combining the two, we arrive at the drift of the ice along the isobar.

The second additional law was arrived at thus In the absence of constant currents and the deflecting influence of land, the ice moves at a speed proportional to the velocity of the wind. The latter, in its turn, is proportional to the gradient of atmospheric pressure; the closer the isobars are drawn on the synoptic chart for any given region, the stronger are the winds in that

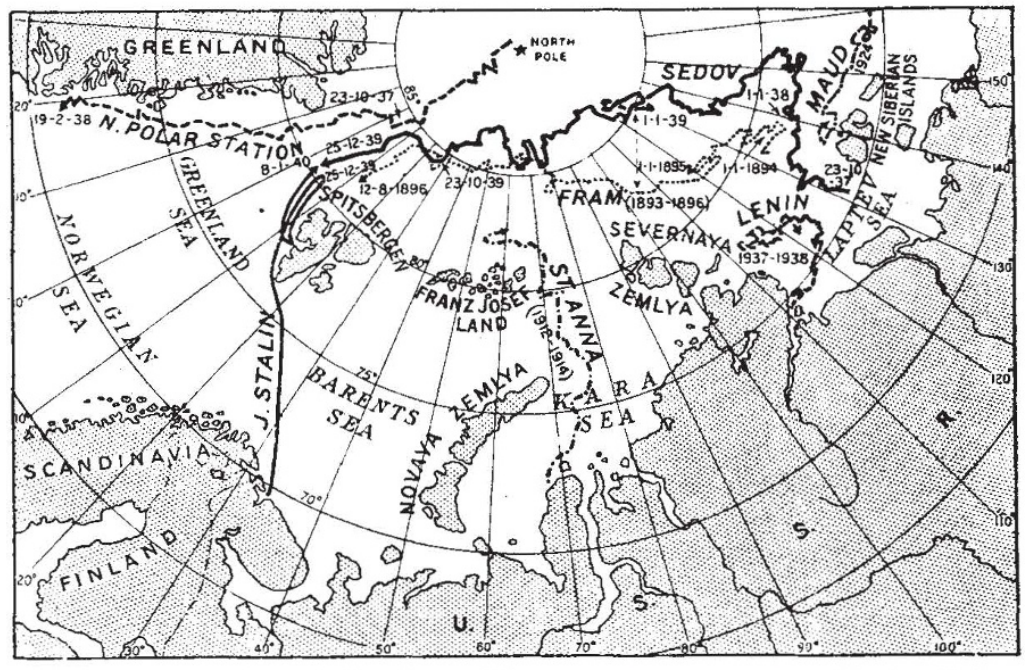

Drffts of the Maud, St. Anna, Fram, the ICE-BREAkers Lenin, Sedov and Papanin's North POLAR Expedition, aNd also the course of THE ICE-BREAKER Joseph Stalin.

region. From this, supported by purely theoretical deductions, it was possible to judge from the synoptic chart not only the direction of the ice drift, but also its speed.

Theoretical calculations made on the basis of the new laws confirm the hypothesis that the ice moves clockwise around the so-called 'pole of inaccessibility'. Had the Sedov in January and February 1939 been somewhat more north than she actually was at that time, it is highly probable that she would have been drawn into this clockwise movement around the 'pole of inaccessibility' and would have been drifting now towards the northern coasts of America.

The new laws offer an explanation of the known drifts of vessels and buoys and also of such aretic phenomena as 'Peary's polynia' at the coast of Greenland, also the 'Great Siberian polynia' stretching with interruptions from the New Siberian Islands to the Chukotsk Sea. These polynias 
coincide with the lines of separation of the ice, or in other words, with the lines of the divergence of the isobars.

The movement of the ice along the isobars also explains why Amundsen's Maud, when entering the ice at Wrangel Island for the purpose of drifting across the North Pole, moved with the ice along the continental slope of the Asiatic coast, that is, along the parallel and not the meridian. It appears that the isobars in the vicinity of Wrangel Island both winter and summer stretch along the parallels. In order to drift with the ice to the North Pole it would be better to enter the ice in the region of the Beaufort Sea, whence, apparently, the icefield occupied by Papanin's North Polar Expedition was carried.

\section{Theoretical Drift and Actual Drift}

On the basis of the monthly charts of pressure, the theoretical drifts were plotted of Papanin's North Polar Expedition (May 21, 1937, to February 1, 1938), of the ice-breakers Sedov (November 1,1937 , to October 1, 1938) and Lenin. Afterwards, according to latitude and longitude, the actual drifts of these vessels were indicated on the chart. The similarity between the lines of the theoretical drifts and those of the actual drifts was noteworthy.

The actual drifts of the Sedov and of the Lenin came very near those calculated by theory. There was, however, considerable difference between the actual and theoretical drifts of Papanin's North Polar Expedition. In the first place, the theoretical drift of Papanin's Expedition came out to the coast of Greenland, and in the second place, it was shorter than the actual drift (if calculated by latitude) by 550 nautical miles. This difference is accounted for by the fact that in calculating the theoretical drifts, account was taken only of the influence of local winds, whereas the movement of the ice is conditioned not only by winds, but also by constant currents.

Naturally, in regions where the constant currents are weak, the influence of local winds on the speed and direction of the drift is paramount. With the approach to the Greenland Sea, the local winds, owing to the strong East Greenland current, have less and less influence on the icefields. The weak winds, the direction of which is contrary to that of the constant current, now only slow down or delay for a time the general drift to the south. This happened in the case of Papanin's North Polar Expedition, and also in the case of the Sedov.

The difference between the actual and theoretical drifts of the Papanin North Polar Expedition is also connected with the speed of the wind drift of mass icefields in the central Arctic. This is one fiftieth of the velocity of the wind causing the drift ; but the speed of the drift of ice under the influence of wind is considerably increased if ahead of the ice, in the direction of the wind, is open sea. In this case, the speed of the drift may reach one tenth of the velocity of the wind or sometimes even more. Conditions such as these are created when north and west winds prevail in the region of the central Arctic adjoining the Greenland Sea, or in the Greenland Sea itself.

In this sea, along the east coast of Greenland right up to lat. $60^{\circ} \mathrm{N}$., summer and winter there moves to the south an uninterrupted line of polar ice carried from the Arctic Basin by the East Greenland current. At the same time, to the north, along the west coasts of Scandinavia and Spitsbergen, flow warm Atlantic waters, which as a deep current later penetrate into the Arctic Basin. Owing to this, the eastern edge of the Greenland ice stretches approximately from Iceland through Jan Mayen Island to the north, up to the northwestern extremity of Spitsbergen. In the summer, the edge recedes to the west, and in the region situated to the north of Spitsbergen, in some years goes up to lat. $82^{\circ} \mathrm{N}$. In winter-time, the edge of the ice in the Greenland Sea moves somewhat to the east and at Spitsbergen descends to lat. $80^{\circ} \mathrm{N}$. and lower. With western and northern winds the edge of the ice recedes to the east, the ice becoming somewhat less closely packed; with eastern and southern winds the edge of the ice recedes to the west and the ice becomes much more closely packed. Thus in the eastern part of the Greenland Sea at any time of the year are immense ice-free stretches of water.

\section{The Greenland Stream}

Every year there flows into the Arctic Ocean about 5,000 cubic kilometres of river water. In addition about 30,000 cubic kilometres of Pacific waters and more than 100,000 cubic kilometres of warm Atlantic waters flow into the Arctic basin through the Bering Strait annually. A small proportion of this water passes into the Baffin Sea but the bulk flows into the Greenland Sea through the broad strait between Greenland and Spitsbergen, forming the East Greenland current. This current is maintained and considerably strengthened by the north and north-west winds which predominate on the east coast of Greenland.

As observations have shown, in the central basin, the speed of the constant current towards the Greenland Sea is not great : it is less than one nautical mile a day. But on approaching the Greenland Sea and within the Greenland Sea, the speed of the constant current increases. According to the calculations of Shirshov and Fedorov (of Papanin's North Polar Expedition), near the 83rd 
parallel the speed of the constant current towards the south reaches $4 \mathrm{~km}$., near the 80 th it is $6 \mathrm{~km}$. and near the 75th parallel it is $9 \mathrm{~km}$. a day.

At the end of August 1939, reaching the northernmost point of her drift, the Sedov began quickly to descend to the south-west, becoming gradually drawn into the Greenland current. From December 1, 1939, the drift proceeded due south, almost parallel to the drift of Papanin's North Polar Expedition, almost at the same speed with which the latter had drifted in that region two years previously.

During the period of its drift, Papanin's North Polar Expedition descended about 1,120 nautical miles to the south latitudinally. This route was covered under the influence of the constant current and local winds. If account is taken of the data of Shirshov and Fedorov concerning the direction and speed of the current, it appears that about 600 nautical miles of the total length of the drift was due to the accompanying sea currents, and only 520 nautical miles to accompanying winds.
At the same time, the theoretical drift for the Sedov was shorter than the actual drift by $\mathbf{5 5 0}$ nautical miles, because when plotting it, we gave consideration only to local winds.

Taking into account the observations and calculations of Shirshov and Fedorov, we attempted to calculate the entire drift of Papanin's Expedition caused, on one hand, by the distribution of atmospheric pressure, and on the other, by the constant current. The results of this calculation made by myself with the help of my assistant, Mr. Somov, are of interest. Comparing the actual position of Papanin's North Polar Expedition on February I, 1938 , with the theoretical position, calculated according to my formulæ, with due account of the constant current, we find that the actual position of the Expedition differed from the theoretical position only by 50 miles in latitude, or only by 5 per cent of the total length of the drift in latitude. This comparison may be regarded as bordering on the limits of accuracy with which the original data were obtained.

\section{DEVELOPMENT OF LONG-RANGE AIRCRAFT*}

\begin{abstract}
A EROPLANES as a means of transport A become increasingly attractive as their range increases. For short journeys the saving in time is often negligible, especially in a country in which other forms of carriage are well developed, but on long routes, particularly trans-oceanic services, the time saved may amount to days or even weeks. Long range demands large fuel capacity, and the peculiar conditions in aircraft may reduce the pay load until it becomes uneconomic, and eventually the limiting range is reached over which no pay load can be carried. The principal problem associated with this is the difficulty of taking a heavily loaded aeroplane off the ground. When flying free, a heavier-than-aircraft is capable of carrying a much bigger load than that which it can lift off the surface of a normal aerodrome. The hazard of a heavily loaded take-off is considerable, particularly when the machine has just left the ground. If at this moment there should be an engine failure (and it is a time when engines appear to be liable to fail, due possibly to some small maladjustment during their overhaul since last being run, which develops into a failure catastrophically) the results will
\end{abstract}

\footnotetext{
* Based upon (1) "Report on the Effects of Large Increments in Wing and Power Loadings on the Performance of Aircraft" by Marcus Langley ; (2) "Static Electricity in Relation to Refuelling in Flight" by Marcus Langley and H. M. Barlow; (3) "Landing Speed and Ceiling in Relation to Refuelling in Flight" by Mareus Langley Flight Refuelling Limited, Ford Aerodrome, Yapton, Arundel, Sussex.)
}

almost certainly be serious, as it is necessary to land at high speed with little or no choice of landing site.

It was with these points in mind that Sir Alan Cobham began several years ago to develop his system of refuelling in flight. His aim was to allow an aircraft to take off light, with very little of the required fuel on board, which on a longrange machine may amount to as much as 25-30 per cent of its all-up loaded weight. Its take-off would thus be comparatively safe, as its preliminary run would be short and the climb away from the ground relatively steep until it has reached a safe operating height. A flying tanker would then come alongside and deliver the fuel to give it range. This scheme has been successful in the regular operation of the North Atlantic service by Imperial Airways Limited last summer, in which the $\$ .30$ flying boats were refuelled at Foynes or Botwood before they commenced the ocean crossing. These flights are to be resumed during this summer, and will probably continue until the ice on Botwood Harbour closes them down for the winter.

Many methods of assisting the take-off have been suggested, and they may be classified under four headings :

(1) Improvement of Thrust. (a) Controllable pitch airscrews. (b) Ground boosting of the power plant, including the use of high-octane fuel. 